\title{
A review of processing and machinery for Jatropha curcas $L$. fruits and seeds in biodiesel production: harvesting, shelling, pretreatment and storage
}

\begin{abstract}
The harvested Jatropha fruits need to be cleaned, dehulled and stored properly as part of the production of Jatropha biodiesel. During processing, the oil yield and quality of the extracted crude oil can be further improved by removing the husks (outer coating) of the seeds before any necessary seed treatment. This report attempts to provide an insight into the major issues of the process from harvesting the Jatropha fruits to the final storage of the seeds and pretreatment of the Jatropha seeds prior to the oil extraction process in production. This report describes a few aspects of the processes including common methods, research and technologies involved so that some improving strategies can be devised. The final part of this report also describes current development trends and the future prospect of Jatropha as a biodiesel. The paper has determined that both the harvest and shelling processes are basically performed manually, especially in rural areas. These activities are time consuming and introduce a high labour cost ( $80 \%$ of the feedstock cost) that can potentially make the Jatropha oil economically uncompetitive. A solution consisting of process mechanisation and mechanical device development are proposed to improve the sustainability of the industry and to meet the increasing world demand. An improvement in oil yield can also be achieved by fruit/seed pretreatment such as drying, shelling and heating. However, improper control may lead to the formation of oxidation products such as free fatty acids which will affect the efficiency of biodiesel production. This is an important sustainability issue which is related to the future development of Jatropha biodiesel.
\end{abstract}

Keyword: Jatropha curcas L.; Process mechanisation; Harvesting; Pretreatment; Shelling process; Seed storage 